\title{
Dividing the Expropriated Areas Based on Multi-Factor Comprehensive Evaluation-A Case Study of Gongcheng Yao Autonomous County
}

\author{
Yuening Song, Xiangwen Cai*, Mi Tang, Mingyuan Liu, Yan Zhao, Zehao Liu \\ Guilin University of Technology, Guilin, China \\ Email: *1315643664@qq.com
}

How to cite this paper: Song, Y.N., Cai, X.W., Tang, M., Liu, M.Y., Zhao, Y. and Liu, Z.H. (2020) Dividing the Expropriated Areas Based on Multi-Factor Comprehensive Evaluation-A Case Study of Gongcheng Yao Autonomous County. Journal of Geographic Information System, 12, 579-596.

https://doi.org/10.4236/jgis.2020.126034

Received: October 17, 2020

Accepted: November 17, 2020

Published: November 20, 2020

Copyright $\odot 2020$ by author(s) and Scientific Research Publishing Inc. This work is licensed under the Creative Commons Attribution International License (CC BY 4.0).

http://creativecommons.org/licenses/by/4.0/

\begin{abstract}
In recent years, with the rapid development of urbanization in China, land acquisition work is particularly important. The division of expropriated area is the primary factor to be considered when evaluating the comprehensive land price of expropriated area. Reasonable division can help to improve the scientific and applicability of the comprehensive land price of the region. How to maximize the protection of farmers' rights and interests by the division of land requisition is an urgent problem to be solved. Taking Gongcheng Yao Autonomous County as an example, this study adopted the multi-factor comprehensive evaluation method to evaluate the division of land requisition in this area, and carried out the corresponding spatial analysis and data processing based on GIS technology. Gongcheng Yao Autonomous County was divided into levy areas, and the Delphi method was used to screen the impact factors and determine the weight of the levy areas. Reasonable division of land requisition area can provide references for land requisition area, make it more scientific and reasonable, and protect the rights and interests of farmers.
\end{abstract}

\section{Keywords}

Area Division, Multi Factor Comprehensive Evaluation, ArcGIS, Delphi

\section{Introduction}

The area is defined as a land area in which the basic conditions such as resource condition, location and economy are in the same position and the compensation 
standard of land requisition is the same. When we evaluate the comprehensive land price of a certain area, we do so according to the criteria defined here. Therefore, it can be said that the division of a region should be the basic work of carrying out comprehensive assessment of the land price of a region, and whether this work is reasonable or not should be an important part of ensuring the scientific suitability of the land price of the region.

At present, in China, there are several ways to do the division of the area: Agricultural land level adjustment method, comprehensive judgment method and multi-factor comprehensive evaluation method [1]. The method of agricultural land level adjustment is based on the administrative boundary line of village. This approach is suitable for areas where agricultural land-level results have been published for implementation. It is therefore clear that the method is not suitable for this study. The comprehensive judgment method is a method of combining the village administrative boundary with relevant experience to divide the requisition area. The comprehensive judgment method combines village administrative boundaries with relevant experience to divide the characteristic areas. If the method of the comprehensive judgment is simply used, in the digital age, it will be very wrong and wrong to deal with it only by experience, so it will be unscientific. Therefore, the comprehensive judgment method is not chosen in this study. The multi-factor comprehensive evaluation method combines the qualitative research method with the quantitative research method, translates the subjective assumption of the complicated thing into the one-way understanding of the complicated thing, and replaces the experience with the scientific index.

Because these three methods have their own advantages and focus, so in the practical part was defined, should adjust measures to local conditions to choose the most scientific and reasonable method, through the comparative analysis and data sorting, data sufficient in Gongcheng Yao autonomous county, on the basis of full investigation at the same time, employing the help of experts, mainly according to the judgment of change law of various factors, and the weight factor. Therefore, this study decided to use the multi-factor comprehensive evaluation method to divide the Area of Gongcheng Yao Autonomous County.

\section{Study on the Method of Regionalization}

According to the rules for grading agricultural land (GB/T28405-2012), rules for the valuation of agricultural land (GB/T28406-2012) and the guidelines of the Ministry of Natural Resources, these regulations point out that the zoning of land requisition must be carried out scientifically and rationally by means of multi-factor comprehensive evaluation method, considering the land use, transportation, population and economy [2].

\subsection{The Main Thought of Multi-Factor Comprehensive Evaluation Method}

When applying this method in village-level areas, it is necessary to have a com- 
prehensive assessment of the factors (such as location, type, supply and demand, etc.) that may affect the compensation standard of land requisition and the current economic situation of the local area. In order to improve the persuasion of the system in practical application, we must use the method of multi-factor comprehensive evaluation to build the system [3].

\subsection{Technical Routes}

Technical route frame diagram of Gongcheng Yao Autonomous County is shown in Figure 1.

\subsubsection{Selection of Basic Units for Zoning}

In the division of regions, the first thing to do is to determine the basic units, which can not only lay the foundation for the subsequent collection of information, but also become the object of the division. As a result, it is finally proposed to use the administrative village as a basic unit, depending on the actual situation. The spatial information and attribute information can be stored by ArcGIS software technology.

\subsubsection{Selection of the Factors for Regionalization}

The determination of technicians and the Delphi method are the main factors for regionalization. The former is carried out by the Working Group; The latter needs to be identified through consultation with experts, who need to be informed about the specific situation of local land requisitions. On the basis of economic development level in recent years, 9 indexes are clearly influenced by the land types, land output value, location conditions, transportation conditions, per capita cultivated land, land supply and demand relations, total output value, peasants' disposable income and cultivated land. According to the data collected from 9 factors, 7 or more factors were selected as the factors of regionalization in Yao Autonomous County of Gongcheng.

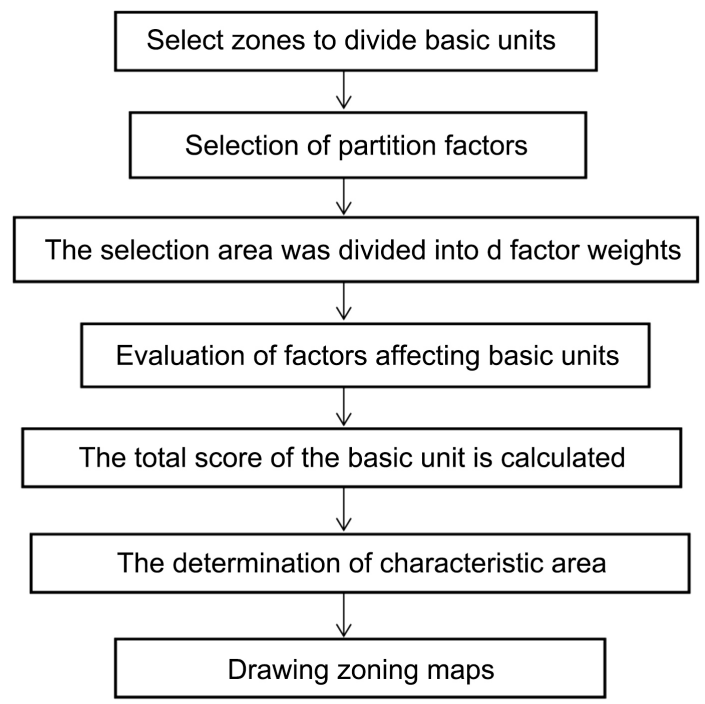

Figure 1. Technical route diagram. 
Delphi method was adopted to select the division factors of this zone. This method can combine the common wisdom of experts to select the factors. After the discussion, the factors that affect the division of the plot will be sorted and selected according to their importance, thus enumerating the factors.

\subsubsection{The Selection of Factor Weight of Zoning}

When measuring the weight of the factors, we should choose a more suitable Delphi method. The weight of factors displayed by the multi-factor comprehensive evaluation method is mainly the size of the specific influence that the single factor of many factors can produce when dividing the area.

\subsubsection{Valuation of Basic Unit Impact Factors}

In the comprehensive evaluation of basic unit by using multi-factor comprehensive evaluation method, we need to determine the appropriate score value of each basic unit on the basis of each index value [4]. Percentage system is used to calculate the score of the factor of the land acquisition area. The results of the survey were analysed and discussed by experts after the fact that the elements of the basic unit were assigned to the field. Moreover, this distribution is not permanent, and the impact of each factor needs to be continuously measured to determine the most appropriate score for each basic unit.

\subsubsection{The Total Score of the Basic Unit Is Calculated}

It is necessary to make a brief analysis on the concrete situation of the basic unit, determine the weighting and assign each factor one by one, and finally calculate the sum of the weighting of the factors so that the total value of the basic unit is calculated. The formula is:

$$
F_{j}=\sum_{i=1}^{n}\left(w_{i} \times q_{i}\right)
$$

where: $F_{j}$ is the total score of the $j$ th basic unit;

$W_{i}$ is the score of factor $i$

$Q_{i}$ is the weight of factor $i$.

\subsubsection{The Determination of Characteristic Area}

The total fractional frequency histogram should be used to display the area visually. After the basic unit total score can not be directly adopted blindly, still need to analyze the concrete situation, check its rationality, analyse the distribution of total score. In view of the unreasonable distribution of partial scores, the adjacent units with similar scores can be moderately adjusted and the integrity of administrative area can be fully considered. The size of the district near the town should be smaller, while the size of the district far away from the town can be larger as much as possible. Gongcheng Yao Autonomous County on the principle that each district doesn't break the village (community) boundary.

\subsubsection{Drawing Zoning Maps}

ArcGIS software is used to draw the map of the area and number the area [5]. 


\section{Case Study}

\subsection{Regional Overview}

The Yao Autonomous County in Gongcheng is located in the northeastern part of Guangxi Zhuang Autonomous Prefecture. The county belongs to mountainous county. The geomorphology is mostly hills and basins. The longitude and latitude of the county are $110^{\circ} 36^{\prime}$ in the west, $111^{\circ} 10^{\prime}$ in the east, $24^{\circ} 37^{\prime}$ in the north and $25^{\circ} 17^{\prime}$ in the north. The county's six towns and three townships are connected by provincial highways, and each village can travel by road.

\subsection{Segmentation}

\subsubsection{Basic Units for Determining Zoning}

This time, 121 administrative units were used as the basic units in the division of the land requisition of Gongcheng Yao Autonomous County.

\subsubsection{Selection of Influencing Factors of Basic Unit}

The factors of the zoning of the expropriation area in Gongcheng Yao Autonomous County include land type, land output value, location condition, transportation condition, cultivated land per capita, relationship between land supply and demand, cultivated land and so on.

1) Types of land

The use of land has become one of the main considerations for the division of expropriated land, and has been influenced by topography, soil and economic output per unit area. But for the convenience of statistical analysis, the land type is divided by reclamation index. Combined with the land information collected in the hand, the reclamation index of each administrative village was calculated and assigned. The reclamation index increases in proportion to the cultivated land and the area of the garden land. It can be clearly seen from Figure 2 that the reclamation index of Gongcheng Town, Limu Town and Lianhua Town is higher on the whole, while that of Ping'an Town, Jiahui town and Longhu Township is higher, while that of Xiling Town, Guanyin Township and Sanjiang Township is lower on the whole.

2) Land value

The land output capacity is mainly considered, and the effects of land type, crop variety and replanting index are also considered. For the convenience of statistical analysis, land output value is divided into unit land area output value. The higher the unit land area output value of the basic unit, the higher the land output capacity, and the higher the allocation value. It can be clearly seen from Figure 3 that the areas with high land output value are concentrated in Gongcheng Town and Ping'an Town, with a score of 100. The second administrative village with a score between 80 and 89 is Lianhua Town, followed by Limu Town, Jiahui Town and Xiling Town. The score of each administrative village ranges from 60 to 69 . However, the regions with low land output value are concentrated in Longhu Township, Guanyin Township and Sanjiang Township. The 


\section{Land type assignment map}

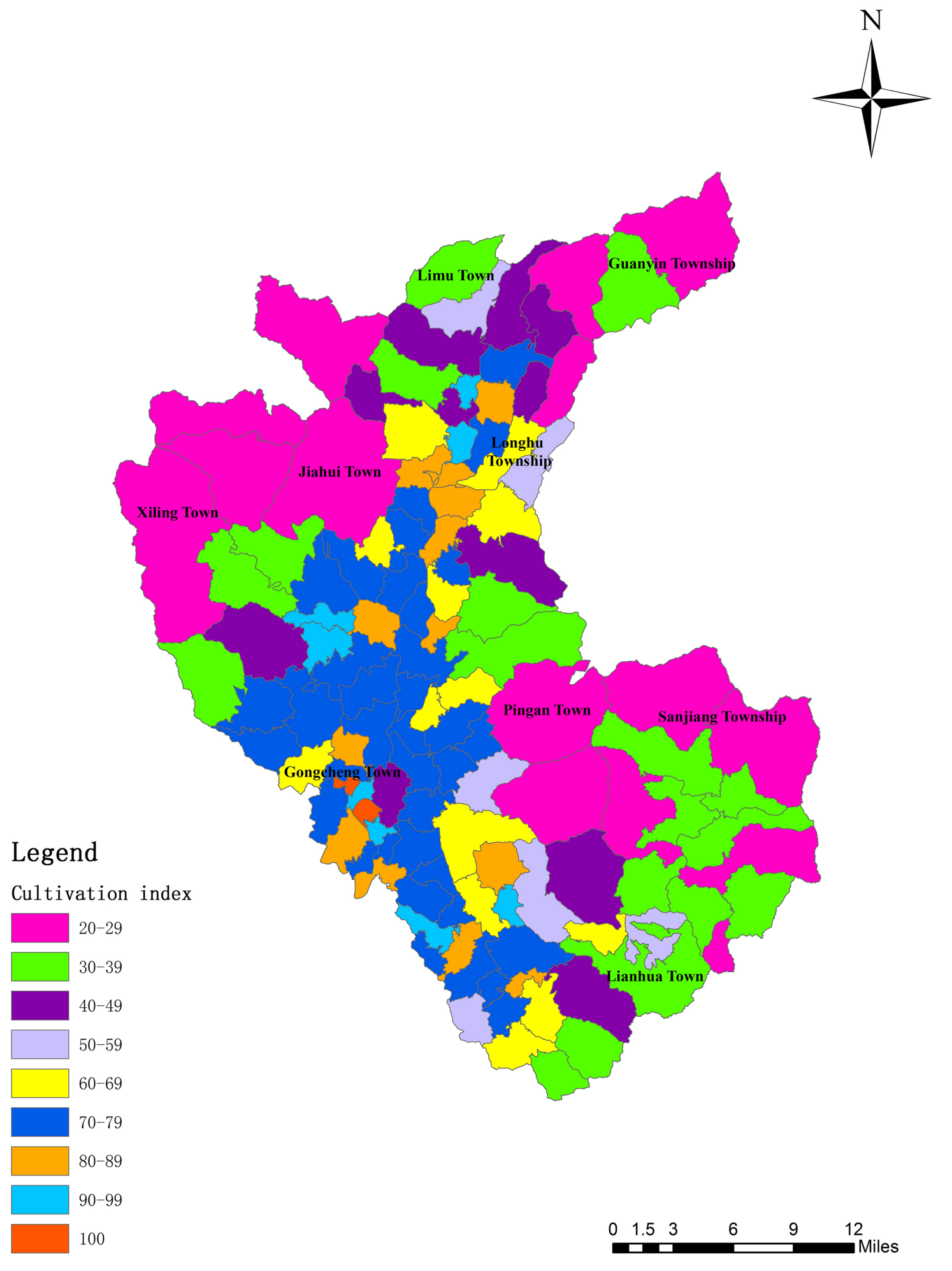

Figure 2. Land type assignment map. 


\section{Land value assignment map}

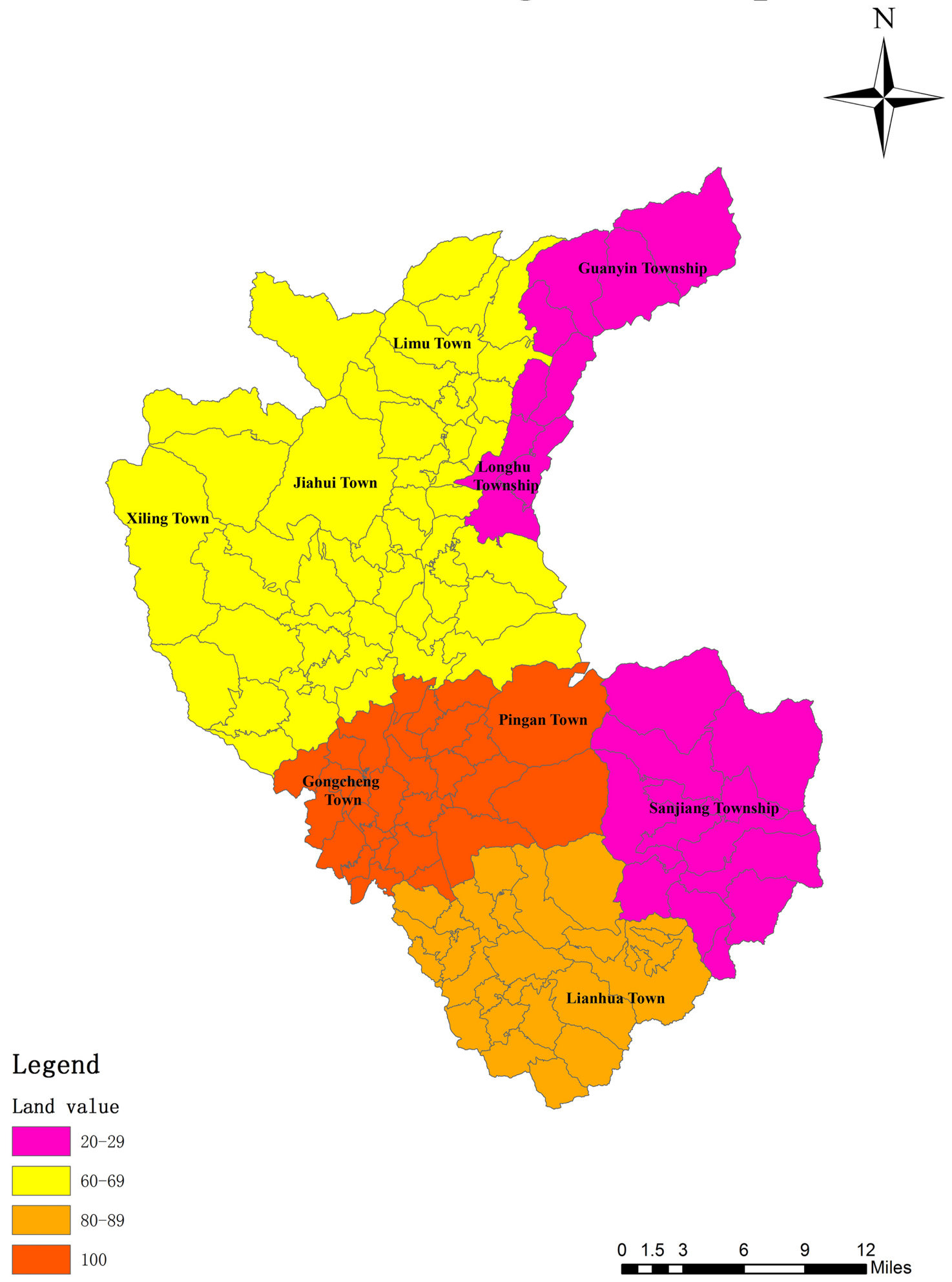

Figure 3. Land value assignment map. 
land output value of the administrative villages of these three townships is within the range of $20-29$.

3) Location condition

The location conditions mainly consider the distance from the center of the city, the distance from other important towns, and the degree of infrastructure complete. As shown in Figure 4, the distance in the central area increases in inverse proportion to the assigned value, the farther the distance, the lower the assigned value. According to the requirements, according to the distance and distance, ArcGIS was used to provide analysis, and the county people's government was used to set up an $8 \mathrm{~km}$ distance buffer. The buffer zone has a score of 100, among them, there are all the administrative villages of Gongcheng Town, including Xiling Town Wagou Village, Bayan Village, Xiasong Village, and Ping'an Town Sanxinqiao village, Lukou village. Again from set up to $16 \mathrm{~km}$ buffer, remove fu is divided into 100 administrative villages, the buffer assigned a score of 80, including the town of peace (except Sanxinqiao Village, Lukou village, Xiashanyuan village, Dajiang village), Xiling Town (with the exception of Wagou village, Bayan village, Xiasong village, Yizi village, Dongmian village, Yingpan village, Deliang village, Luobo village, Daoping village), Sian Village of the Jiahui Town, Songlin village, Baiyang village, Lianhua Town Lianhua village, Jiantou village, Dushi village. Establish a buffer for the third time, the scope of radiation $24 \mathrm{~km}$, remove the assignment is divided into 100 , 80 administrative villages, buffer in the score of 60 , including Jiahui Town (in addition to Sian village, Songlin village, Baiyang village, Xinan village), Yingpan Village, Xiling Town, Deliang village, Luobo village, Daoping village, Limu Town of the Liangxi village, Liuling village, Ping'an Town Xiashanyuan village, Dajiang village, and half of the administrative villages in Lianhua Town. Finally once again establish a buffer, the scope of radiation for $32 \mathrm{~km}$, excluding administrative villages assigned to 100,80 and 60, the buffer zone is assigned a score of 40, including Longhu Township Longling village, Longhu village, Shizi village, Limu Town of the Dajian village, Wufu village, Shangguan village, village of Gaoling, Jianan village, Changjia village, Jiahui Town Xinan village, Yizi village of the Xiling Town, Dongmian village, Sanjiang Township, Dadi village, Huangping village, Litian village, Xijiaoling village and Sanjiang Township estuary mining and breeding field, and remaining Lianhua Town administrative villages. The remaining administrative villages were given a score of 20 points.

4) Traffic conditions

Most of the time, road accessibility and external patency are two important indexes that will have important influence on local traffic conditions. The basic unit road access measurement is mainly considered. In general, road access is reflected by road grade, different road grade, different degrees of convenience, the higher the basic unit access road grade, the higher the assignment value. By using ArcGIS software, the road network is superposed on the bottom map of the administrative district, analyzed by using buffer zone, and radiated $1.5 \mathrm{~km}$ from 


\section{Location condition assignment map}

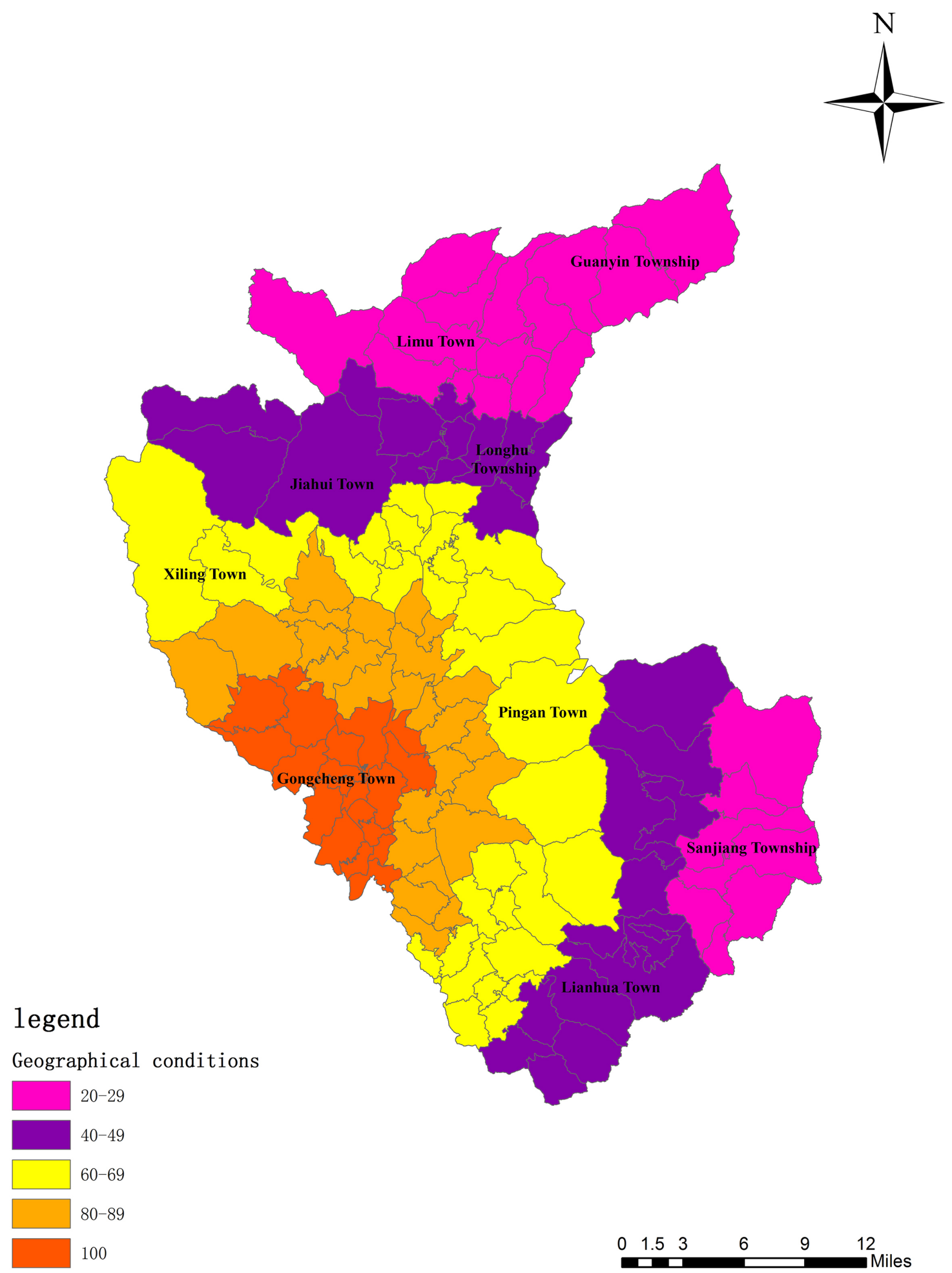

Figure 4. Location condition assignment map. 
the center of the road network, and divided according to the grade of the road. The National Road is 100 points, 20 points for each level. As shown in Figure 5, Limu town has a national road through which the radiation of the administrative villages assigned a score of 100; The provincial roads are mainly distributed in Gongcheng Town, Jiahui Town and Longhu Township, involving the administrative villages, with a score of 80 . Lianhua Town, Ping'an Town, Sanjiang Town and Xiling Town all pass county road, with a score of 60 . Guanyin Township road, the score is 40 .

5) cultivated land per capita

The per capita cultivated land is divided by the area of cultivated land in the basic unit by the household registration population. The per capita cultivated land area is the most important factor in the per capita cultivated land index. According to the per capita cultivated land area of each basic unit to compare and divide into different grades to determine the allocation, the cultivated land area increases in inverse proportion to the allocation value. The administrative villages in the project area are divided into 100 districts, namely Lianhua Town and Ping'an Town. Gongcheng Town and Longhu Township scored between 80 and 89. The value of the Jiahua Town is between 70 and 79. Those with scores ranging from 60 to 69 were Xiling Town and Sanjiang Township. The score of Guanyin Township ranges from 40 to 49 . Finally, the administrative villages with the lowest per capita farmland score were concentrated in Limu Town, with a score between 20 and 29 (Figure 6).

6) Land supply and demand

The intensity of land demand should be judged according to the relationship between supply and demand and the frequency of land requisition cases. This research is divided by adopting the data of land expropriation projected in Gongcheng Yao Autonomous County in 2015-2019. The larger the levy area, the more tense the land demand, the higher the grade, the higher the assignment value, the opposite, even zero. Based on the classification and classification of land levy area, drawing Figure 7 is made by ArcGIS. It can be seen that the land demand of the administrative villages in Ping'an Town is the most tense, with the value of 100. Secondly, the administrative villages where the land demand is more tense are distributed in the towns of Gongcheng Town and Lianhua Town, and the distribution of the value is in the range of $60-69$. The distribution of scores in the administrative villages of 40 - 49 is mainly concentrated in the towns of Xiling and Longhu Township. The ratings of the administrative villages in Jiahui Town, Sanjiang Township and Guanyin Township are 30 - 39. Finally, the administrative villages in the town of Limu are assigned a score range of $20-29$.

7) Cultivated land (natural quality of cultivated land)

Cultivated land and so on can divide the quality of agricultural land and so on. The key point of determining the grade of cultivated land is to measure the nature of the land. In general, cultivated land is divided into 1 - 15 not equal, and the closer it is, the higher it is, the higher the corresponding score. Using ArcGIS to divide the cultivated land and assign the value, through Figure 8, we can see 


\section{Traffic condition assignment map}

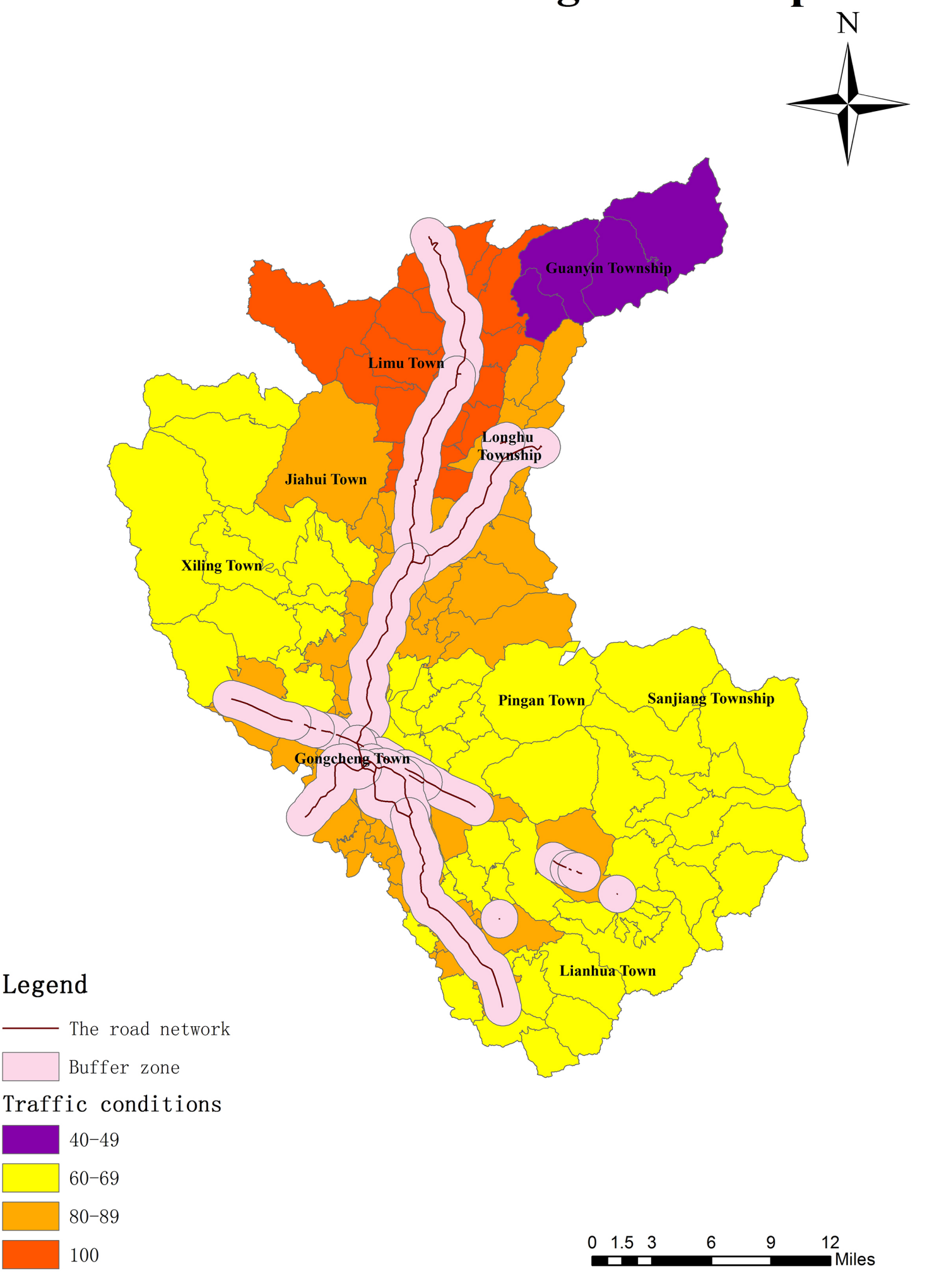

Figure 5. Traffic condition assignment map. 


\section{Per capita cultivated land valuation map}

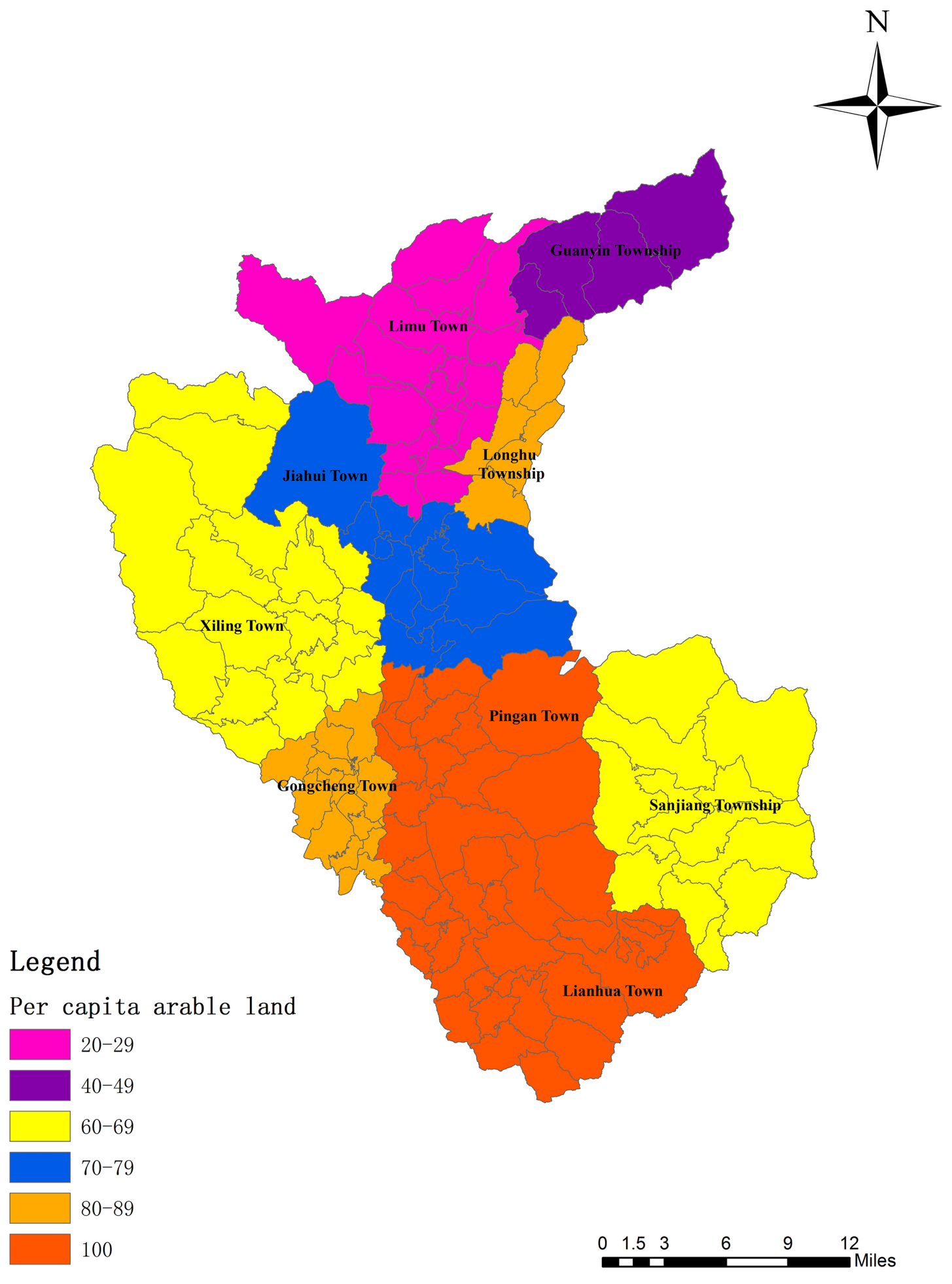

Figure 6. Per capita cultivated land valuation map. 


\section{Land supply and demand valuation map}

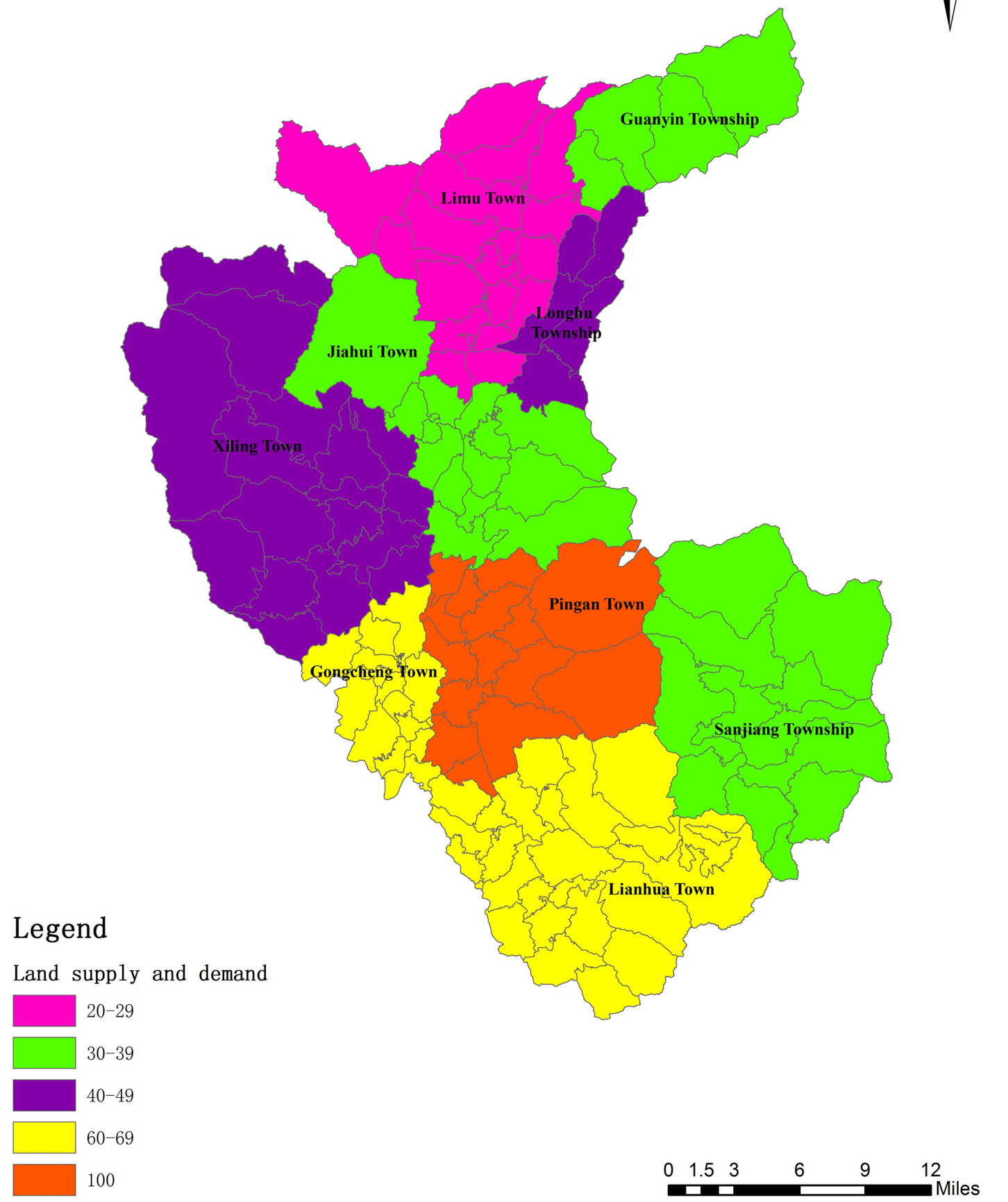

Figure 7. Land supply and demand valuation map. 


\section{Cultivated land grade assignment map}

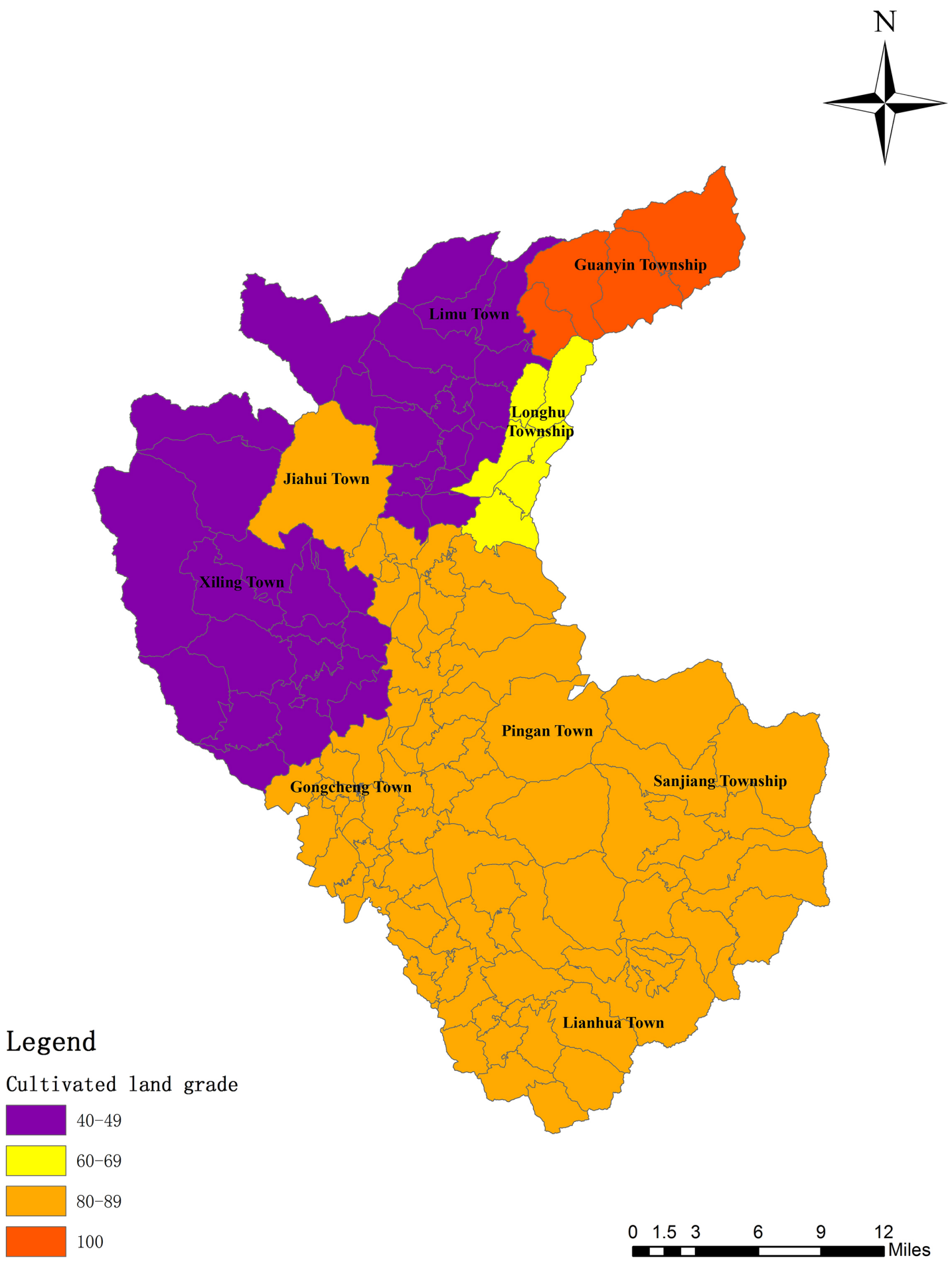

Figure 8. Cultivated land grade assignment map. 
that the cultivated land and so on the highest is Guanyin Township, the assigned value is 100. The grade of cultivated land in Gongcheng Yao Autonomous County is mainly in the range of 80 - 89 , including Gongcheng Town, Ping'an Town, Lianhua Town, Jiahui Town and Sanjiang Township. The value of cultivated land in Longhu Township is in the range of $60-69$. The lowest scores were assigned to Xiling Town and Limu Town, with a score of 40 - 49 [6].

\subsubsection{The Determination of the Weight of the Influencing Factors of the Basic Unit}

Delphi method is to determine the factor weight of zoning according to expert score. According to the actual situation of land in the county, the weights are determined as: $20 \%$ of land type, $20 \%$ of land output value, $15 \%$ of location condition, $15 \%$ of transportation condition, $10 \%$ of cultivated land per capita, $10 \%$ of land supply and demand relationship, $10 \%$ of cultivated land and $10 \%$ of cultivated land.

\subsubsection{Calculate the Total Score of the Base Unit and Divide the Zoning Area}

Firstly, the total score value of each basic unit is calculated by using the formula. Then the total score value is analyzed by using the total score frequency curve method. Generate a frequency histogram in Arc GIS, as shown in Figure 9. According to the frequency histogram, the proper demarcation point is determined to divide the Yao autonomous county of Gongcheng into four grades. [7] In Arc GIS, the color of each grade is modified, the map name, legend, needle and scale are added, and the final map of the area is output.

The total score range of the primary region is between $73-83$ points, with 27 basic space units; The total score range of secondary region is $63-72$ points, there are 20 basic space units; The total score range of the three-tier region is between 53 - 62 points, with 46 basic space units; The total score range of the four-tier region is between 38 - 52, with a total of 28 basic space units.

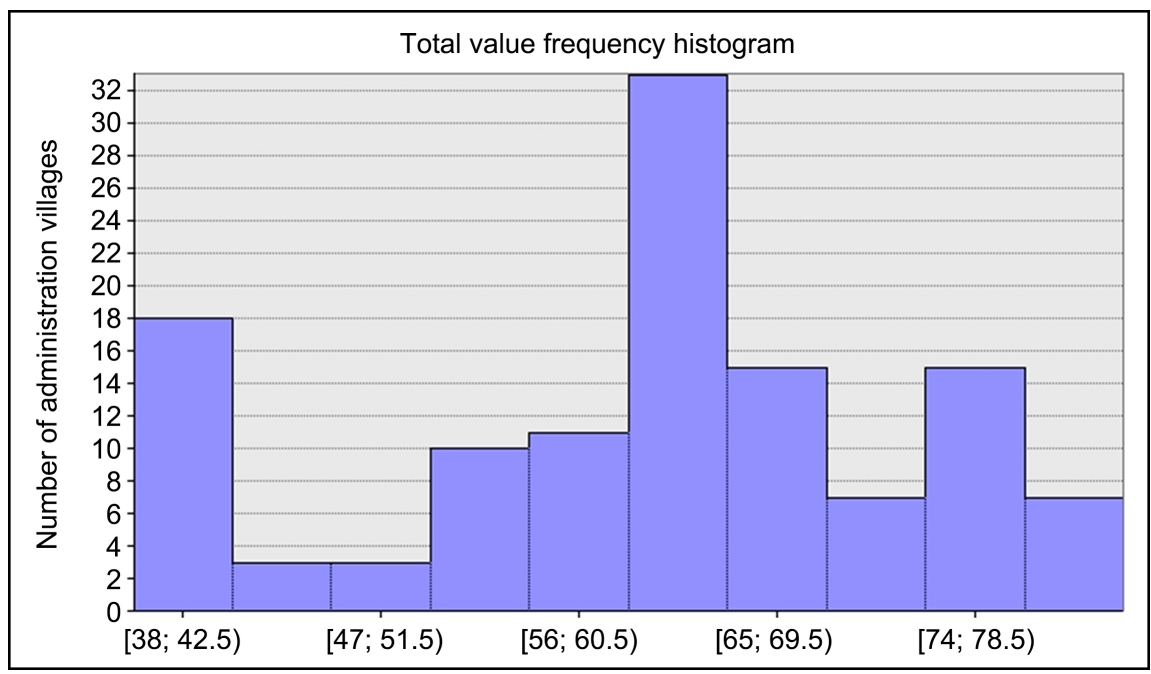

Figure 9. Total value frequency histogram. 
The distribution of the first-level areas is in the town of Gongcheng (except Xiashanyuan village and Dajiang Village); the distribution range of the second-class area is Xiashanyuan village, Dajiang village, Lianhua Town (except Huangnigang village, Pingchong village, Lianhua Town estuary mining plant, Landong village, Sangyuan village and Puyuan village); the three-tier areas are distributed in the following areas: Huangnigang village, Pingchong village, Lianhua Town estuary mining plant, Landong village, Sangyuan village, Puyuan village, Limu Town (except Quanhui village), Jiahui Town (except Xinan village), Xiling Town (except Yizi village, Dongmian village, Yingpan village, Deliang village and Daoping village); the four-tier areas are located in Limu Town Quanhui village, Jiahui Town Xinan village, Xiling Town Yizi village, Dongmian village, Yingpan village, Deliang village, Daoping village, Longhu Township, Guanyin Township and Sanjiang Township (Figure 10).

\section{Analysis and Discussion}

In this study, the results obtained from the multi-factor comprehensive evaluation of the zoning of Gongcheng Yao Autonomous County are strongly guided by the local zoning classification, and the results are basically consistent with those published by the government. This method and result have been generally accepted by villagers and effectively protected the legal rights and interests of peasants [8] [9] [10].

Hai-jun wang et al. [1] studied the local zoning by means of multi-factor comprehensive evaluation, which proved the feasibility and validity of this method. They believe that the multi-factor comprehensive evaluation method can meet the basic requirements of regionalization and is a simple and practical method.

The zoning of the zoning needs to be carried out according to the specific policies, and the zoning needs to be carried out actively in the process of the zoning, which requires the selection of factors to be scientifically quantified. At the same time, the application of ArcGIS software can greatly improve the work progress of zoning, quicken the work progress and improve the work efficiency [11]. Data generated by the software can be stored more conveniently to facilitate subsequent revisions or updates [12].

Therefore, using multi-factor comprehensive evaluation method combined with ArcGIS software, and using Delphi method to screen out the influence factors and determine the weight of the zoning, the zoning result has strong rationality and high operability.

\section{Conclusion}

In this paper, the multi-factor comprehensive evaluation method is used to divide the land area of Gongcheng Yao Autonomous County, and it is concluded that the distribution scope of the first-level area is mostly distributed in the west of Gongcheng Town and Ping'an Town. The distribution range of the secondary area is east of Ping'an Town and north of Lianhua Town. The distribution range 


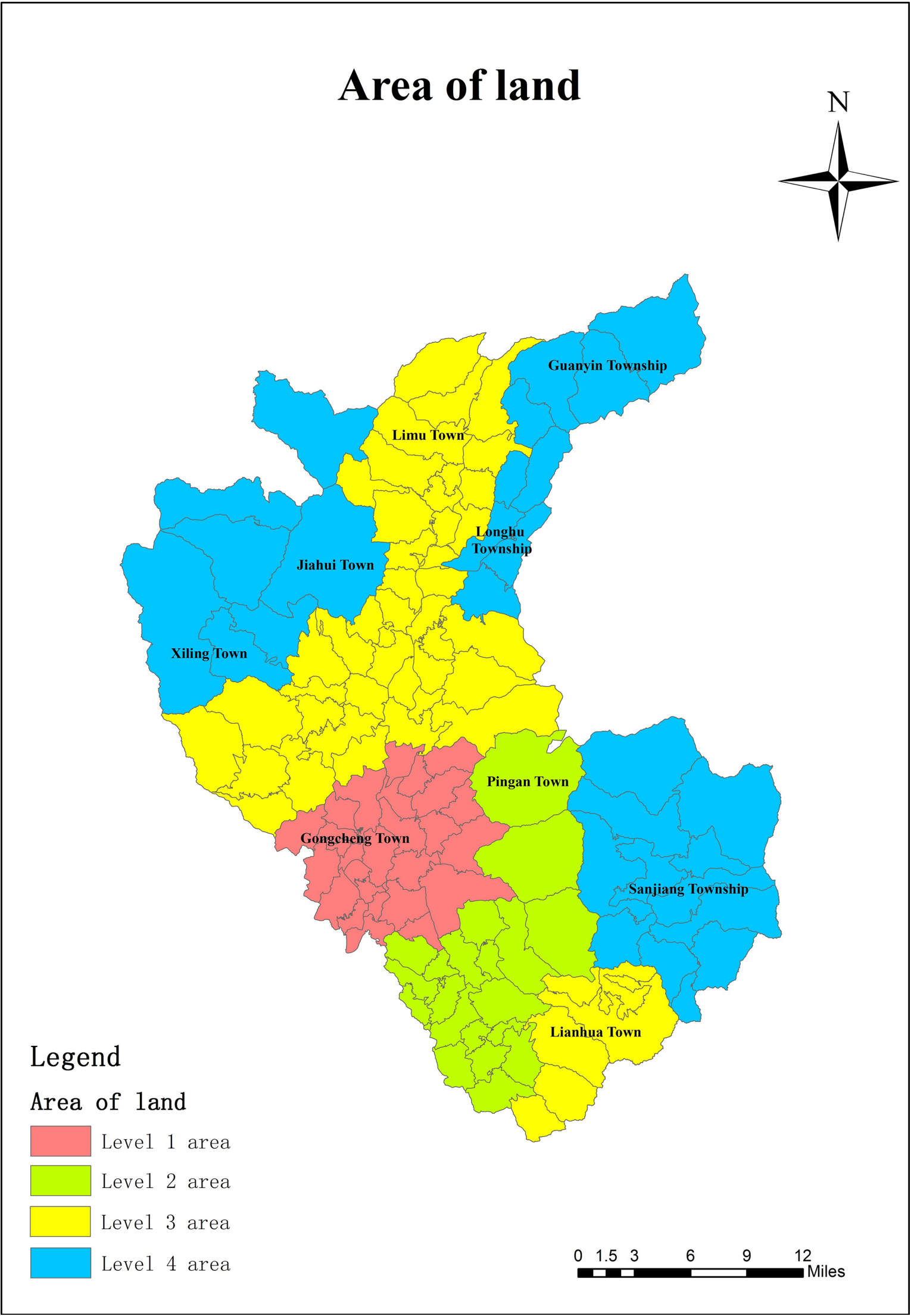

Figure 10. Area of land. 
of the tertiary area is the south of Lianhua Town, the south of Xiling Town, Jiahui Town and most areas of Limu Town. The distribution scope of forth-level area is the northern part of Xiling Town, the remaining area of Jiahui Town and Limu Town, Longhu Township, Guanyin Township and Sanjiang Township.

\section{Conflicts of Interest}

The authors declare no conflicts of interest regarding the publication of this paper.

\section{References}

[1] Wang, H.J. and Zhang, D.L. (2006) A Study on the Method of Division of Regions by Multi-Factor Comprehensive Evaluation. Journal of Huazhong Normal University (Natural Science), 40, 614-616.

[2] Wang, J.Q. (2014) Grading and Evaluation of Agricultural Land in Hangjin Banner. Inner Mongolia Normal University, Inner Mongolia.

[3] Ke, Y. (2006) Current Situation and Improvement of Land Expropriation Compensation Standard in China. Chongqing University, Chongqing.

[4] Feng, H.M., Nie, Y.M., Chen, H.Y., et al. (2014) A Study on the Zoning of Land Acquisition Based on ArcGIS: A Case Study of Pingyi County. Agricultural Sciences, 42, 1823-1829.

[5] Wang, L.M. (2007) Comprehensive Land Price Assessment Study of Agricultural Land Sections in Changchun. Jilin University, Jilin.

[6] Wang, H.J. (2006) Research on Urban Land Classification Based on Spatial Clustering. Journal of Wuhan University. Information Science Edition, 31, 628-631.

[7] Peng, J.Z. (2006) A Study of Partial Pricing. Nanjing Normal University, Nanjing.

[8] Liu, P., Liu, X.P. and Long, S. (2005) An Empirical Study on the Methods for Determining Land Price of Particular Syndromes. Land Sciences, 19, 30-35.

[9] Tyler, M., Hunter, L., Steiner, F., et al. (1987) Use of Agricultural Land Evaluation and Site Assessment in Whitman County, Washington, USA. Environmental Management, 11, 407-412. https://doi.org/10.1007/BF01867169

[10] Jacksonsmith, D.B. and Busch, G. (2003) Cache County, Utah Agricultural Land Evaluation and Site Assessment Handbook. Cache County Agricultural Advisory Board, 1-27.

[11] Feng, H.M. (2014) A Study on Zoning and Comprehensive Land Pricing Based on ArcGIS. Shandong Agricultural University, Shandong.

[12] Ren, H., Li, X.G., Pan, J.H., et al. (2008) An ArcGIS-Based Study on the Division of Agro-Land-Use Plots. Land and Resources Science and Technology Management, 25, 46-50. 